\title{
ISSO É BRASIL [?]: SEQUÊNCIA DIDÁTICA SOBRE O COMBATE ÀS DROGAS NA EDUCAÇÃO DE JOVENS E ADULTOS
}

\author{
THIS IS BRAZIL [?]: TEACHING SEQUENCE OR DRUG FIGHTING IN YOUTH AND ADULT EDUCATION
}

\section{ESTO ES BRASIL [?]: SECUENCIA DIDÁCTICA EN LA LUCHA CONTRA LAS DROGAS EN LA EDUCACIÓN DE JÓVENES Y ADULTOS}

\author{
Mauricio de Oliveira Silva1 ${ }^{1}$ \\ Marcos Anjos de Moura2
}

\begin{abstract}
${ }^{1}$ Doutorando em Agroecologia e Desenvolvimento Territorial (UNIVASF). Mestre em Ciências Ambientais (UESB). Especialista em Educação e Direitos Humanos (Alfa América). Licenciado em Ciências Biológicas (UESB). Professor da rede municipal de Vitória da Conquista - BA (SMED), Vitória da Conquista, Bahia, Brasil.
\end{abstract}

${ }^{2}$ Doutorando em Ecologia e Conservação da Biodiversidade (UESC). Mestre em Ciências Ambientais (UESB). Licenciado em Ciências Biológicas (UESB); *Autor correspondente: m.osilva@hotmail.com

Recebido: 02/09/2021 | Aprovado: 17/10/2021 | Publicado: 09/11/2021

\begin{abstract}
Resumo: Uma problemática com o combate as drogas e suas implicações estão intimamente ligadas a saúde, a segurança pública e as desigualdades sociais do país, sendo importante elencar negações de direitos, violência urbana e as vulnerabilidades que o país não consegue sanar por meio de políticas públicas, uma delas é a dependência química. Este artigo apresenta uma sequência didática (SD) com o objetivo de promover debates sobre o combate as drogas, interligar o tráfico com as questões culturais e sociais e propor reflexão sobre a condição das pessoas de baixa renda, mais vulneráveis, as ações de combate atualmente propostas. A SD foi aplicada para 34 alunos, idades entre 16 a 17, Educação de Jovens e Adultos, $8^{\circ}$ e $9^{\circ}$ ano do Ensino Fundamental da Educação Básica. A atividade apresentada como um relato de experiência com análise qualitativa e descritiva. A aplicação da SD, com a utilização de mídias em sala de aula se mostraram de bom aproveitamento, usando letras de músicas populares de estilos que permeiam o funk, o rap e o hip hop foi possível fazer uma aproximação com os estudantes, que apresentaram interesse nas discussões propostas pelos versos, sons e imagens que constituem as obras audiovisuais. Os filmes "A vida é feita de escolhas" e "Escritores da Liberdade" foram importantes para refletir sobre problemas com drogas e interligar com as problemáticas sociais. Dessa forma, a SD fica como sugestão a ser trabalhada em outras turmas para possíveis ampliações e ajustes do projeto.
\end{abstract}

Palavras-chave: Ensino. Prevenção. Consumo. Repressão.

Abstract: A problem with the fight against drugs and its implications are closely linked to health, public safety and social inequalities in the country, it is important to list denials of rights, urban violence and the vulnerabilities that the country cannot remedy through policies one of them is chemical dependency. This article presents a didactic sequence (SD) with the aim of promoting debates on the fight against drugs, connecting trafficking with cultural and social issues and proposing a reflection on the condition of the most vulnerable low-income people, the combat actions currently proposals. The SD was applied to 34 students, ages 16 to 17, Youth and Adult Education, 8th and 9th grade of Basic Education. The activity presented as an experience report with qualitative and descriptive analysis. The application of SD, with the use of media in the classroom, proved to be successful, using lyrics from popular songs in styles that permeate funk, rap and hip hop, it was possible to approach the students, who showed interest in the discussions proposed by the verses, sounds and images that constitute the audiovisual works. The films "Life is made of choices" and "Writers of Freedom" were important to reflect on drug problems and interconnect with social problems. Thus, the SD is a suggestion to be worked on in other classes for possible expansions and adjustments to the project.

Keywords: Teaching. Prevention. Consumption. Repression.

Resumen: Un problema con la lucha contra las drogas y sus implicaciones están estrechamente vinculadas a la salud, la seguridad pública y las desigualdades sociales en el país, es importante enumerar las denegaciones de derechos, la violencia urbana y las vulnerabilidades que el país no puede remediar a través de políticas uno de ellos es la dependencia química. Este artículo presenta una secuencia didáctica (DS) con el objetivo de promover debates sobre la lucha contra las drogas, conectando el tráfico con cuestiones culturales y sociales y proponiendo una reflexión sobre la condición de las personas 
de bajos ingresos más vulnerables, las propuestas de acciones de combate actuales. El SD se aplicó a 34 alumnos, de 16 a 17 años de Educación Juvenil y de Adultos, $8^{\circ}$ y $9^{\circ}$ de la Escuela Primaria de Educación Básica. La actividad presentada como relato de experiencia con análisis cualitativo y descriptivo. La aplicación de SD, con el uso de medios en el aula, resultó exitosa, utilizando letras de canciones populares en estilos que impregnan funk, rap y hip hop, fue posible acercarse a los estudiantes, quienes mostraron interés en las discusiones propuestas. por los versos, sonidos e imágenes que constituyen las obras audiovisuales. Las películas "La vida está hecha de elecciones" y "Escritores de la libertad" fueron importantes para reflexionar sobre los problemas de las drogas e interconectarse con los problemas sociales. Así, el SD es una sugerencia a trabajar en otras clases para posibles ampliaciones y ajustes al proyecto.

Palabras clave: Docencia. Prevención. Consumo. Represión.

\title{
1 INTRODUÇÃO
}

É pelo olho meio fechado, pela mira da arminha gesticulada com a mão, que a sociedade olha para periferia, nesse fogo cruzado, o morador está entre polícia e o grito de "pega ladrão", situação cotidiana de ações antidrogas. O Estado viola inúmeros direitos humanos contra a periferia justificado pela guerra contra as drogas, não foi a favela que declarou essa guerra, muito menos quem separou entre drogas lícitas e ilícitas, mas para nós, o outro lado dessa guerra é feroz e significa escolas fechadas, mudanças de rotinas e preocupação com familiares que vão apenas comprar pão e são declarados como mera estatística (Movimentos, 2017).

Um dos desafios do Brasil é combater as drogas e diminuir o tráfico dentro de suas fronteiras, concomitante a isso, a problemática com as drogas e suas inter e intra relações estão intimamente ligadas a saúde, a segurança pública e as desigualdades sociais do país. Garcia et al. (2008, p. 274) defendem que ao se tratar da política antidrogas, deve-se ter:

\begin{abstract}
uma política que articule uma proposta de prevenção ampla, preservadora dos direitos humanos, permanente e realista; que dê atenção aos usuários de drogas reduzindo os danos à sua saúde e à sociedade, que promova a inserção de grandes setores da sociedade de forma a proporcionar alternativas de vida e a evitar deixá-los à mercê do tráfico como forma de subsistência (Garcia et al., 2008, p. 274).
\end{abstract}

Dentro disso, a escola por meio da educação é uma peça-chave na prevenção, sendo entendida como um meio de "emancipação, humanização, um ato de cuidado para si e para outro. Assim, ela tem o papel de tornar o ser humano apto a pensar e agir frente aos acontecimentos da sociedade, buscando soluções de forma compartilhada para os problemas de seu tempo histórico" (Marghoti et al., 2018, p. 15).

Salienta-se que "a prevenção ao uso de drogas faz-se necessária desde muito cedo na vida dos educandos, pois as facilidades e promessas que permeiam o mundo das drogas podem seduzir os jovens" (Silva \& Ferreira, 2017, p. 1).

Por este viés, ao se debater o tema combate as drogas é importante elencar negações de direitos, violência urbana e as vulnerabilidades que o país não consegue sanar por meio de políticas públicas, uma delas é a dependência química. "A dependência química deve ser vista como uma condição biopsicossocial e, portanto, transcende o "paradigma médico" comum, de forma a exigir uma abordagem sistêmica e multidisciplinar" (Lima, 2010, p. 298).

No artigo de Lima (2010) é discutido que para combater o alto consumo de drogas deve-se modificar o modelo econômico, que causa a sensação de mal-estar e gera um incômodo diante a classe social que a pessoa se encontra, estas induzidas pelas propagandas que teoricamente criam status pelo consumo; para alívio deste, os 
mecanismos de recompensas podem ser "saciados" com o uso de drogas, essas demandas criadas pela cultura podem também ser "preenchidas" por poder de compra (consumo), malhação em academias, na internet, no trabalho, sexo, comidas, etc.

Nessa sociedade do consumo, capitalista, o status pode ser dado pelo espetáculo. O espetáculo é o conjunto das relações sociais mediadas pelas imagens (Debord, 2003). Na nova economia do capitalismo, já não se trata apenas de produzir pelo menor custo bens materiais, mas de solicitar as emoções, estimular os afetos e os imaginários, fazer sonhar, sentir e divertir (Lipovesty \& Serroy, 2013). Aqui, a droga faz parte do espetáculo e dá uma visão de pessoa cult, poderosa, sensual, rica, entre outros adjetivos que satisfazem o ego humano.

Nesse contexto, as drogas e seus usos recreativos podem demonstrar e promover alguns tipos de poder simbólico. O poder simbólico é um poder da construção da realidade que tende a estabelecer uma ordem gnoseológica: o sentido imediato do mundo, particularmente do mundo social (Bourdieu, 1989, p. 09). O debate proposto durante a Sequência Didática (SD) aplicada foi ampliar a visão das questões sociais, culturais, de saúde, ambientais que estão arraigadas com a temática.

Para Lima (2010), somam-se como estratégias de combate as drogas, ações de educação, de informação e de prevenção, indispensáveis para o enfrentamento das drogas, além do combate ao tráfico e outras práticas associadas ao mesmo (corrupção, lavagem de dinheiro, tráfico de armas...).

É importante ressaltar que a complexidade e a magnitude das problemáticas das drogas, especialmente à violência, as organizações sociais e o Governo, além das instituições da Sociedade Civil, de acordo com Lima (2010), devem estar envolvidas continuamente com as ações de combate as drogas, em seus diversos lados: educação, prevenção, segurança, atendimento, inserção social, etc.

Relacionando com o que foi discorrido. Segundo o VI Levantamento Nacional sobre o Consumo de Drogas Psicotrópicas (2010), realizado em 27 capitais brasilerias com estudantes do Ensino Fundamental e Médio da rede pública e privada, relatou que os meninos possuem maior predisposição ao uso de drogas, enquanto, as meninas preferem usar medicamentos controlados sem prévia autorização médica. Inferindo que, o uso de drogas por adolescentes está estritamente ligado por questões e motivos “sociais", associado a isso, quando questionada suas motivações foram obtidas respostas pontuais, como: i) valorização social relacionado ao pertencimento e ao fazer parte de algo ou grupo, ii) busca pelo prazer, iii) alívio do tédio, iv) problemas pessoais, v) diversão, vi) curiosidade para experimentar, vii) diversão e, viii) relaxamento.

Ainda, segundo o levantamento, as drogas mais utilizadas pela juventude, além das lícitas, como por exemplo, tabaco e álcool, foram citadas: maconha, solventes, anfetamínicos, ansiolíticos, bebidas energéticas e anticolinérgicos. Relataram os fatores relacionados a intensidade e vontade de consumo dessas drogas, sendo eles, festas ou ocasiões propícias, amigos que fazem uso dessas substâncias, tempo livre, problemas pessoais relacionados ao luto ou separação dos responsáveis, uso rotineiro e dependência e pensamento/sentimentos negativos, como solidão, raiva e ansiedade.

Por fim, o levantamento realizado sobre o consumo de drogas aborda sobre a prevenção relacionada com o acolhimento da família, escola e na unidade de saúde, entrando em consenso sobre ajuda profissional 
qualificada e multidisciplinar com acompanhamentos periódicos para identificar a origem do problema e tratar como doença, considerando o usuário como responsável e pensar na dignidade da pessoa humana em fazer suas próprias escolhas e no tratamento a longo prazo, que pode ocorrer recaídas.

Nesse contexto é primordial utilizar-se de alternativas didático pedagógicas que visam contrinuir com o processo de ensino e aprendizado, dentre elas as Sequências Didáticas (SD) têm demonstrado bons resultado no que tange o ensino de Biologia (Moura et al., 2017). As SD compreendem um conjunto de atividades e intervenções visando alcançar objetivos educacionais, divididas em momentos ou etapas para mediar e explanar o conteúdo abordado para melhor entendimento dos alunos. Assim, o alunado é integrante do processo e contribuem com conhecimentos do cotidiano e assuntos de interesse da comunidade para construção do conhecimento científico (Moura et al., 2017).

Ademais, o conteúdo combate as drogas e sua relação com a educação e prevenção deve ser abordado no contexto escolar para formar cidadãos responsáveis por discernir entre o bom e o ruim sobre as inúmeras vertentes do assunto levantando quetionamentos sobre o papel da escola e como auxiliar os estudantes na prevenção para diminuir ou coibir o cosumo de drogas.

Pensando nessas medidas preventivas, as atividades da sequência didática (SD), aqui descritas, teve como objetivo promover debates sobre o combate as drogas no Brasil, interligar o tráfico com as questões culturais e sociais e propor reflexão sobre a condição das pessoas de baixa renda, mais vulneráveis, as ações de combate atualmente propostas.

\section{METODOLOGIA}

As aulas foram preparadas para 34 alunos, com idades entre 16 e 17, da Educação de Jovens e Adultos (EJA), $8^{\circ}$ e $9^{\circ}$ ano do Ensino Fundamental, de uma Escola Municipal localizada no Bairro Jardim Valéria, Vitória da Conquista, Bahia, Nordeste do Brasil. Para tal, foi planejado uma Sequência Didática (SD), distribuída em 8 encontros totalizando 11 horas/aulas. A SD foi organizada de modo que atendesse ao mundo adolescente. Para isso, utilizou-se de música, videoclipes e discussões para motivar a participação dos discentes na temática sobre as drogas e suas relações com a sociedade e subtemas (Quadro 1).

A SD é "um conjunto de atividades ordenadas, estruturadas e articuladas para a realização de certos objetivos educacionais, que têm um princípio e um fim conhecidos tanto pelos professores como pelos alunos" (Zabala, 1998, p. 18). Ela deve ter um enredo pré-estabelecido, com material, método e aplicação que pode ser seguida, exequível, adaptável e replicada.

O quadro 1 apresenta as atividades que foram realizadas na escola durante a abordagem do tema "Drogas e Sociedade". 
Quadro 1 - Sequência Didática (SD) construída para abordagem sobre a prevenção ao uso de drogas e suas inter-relações com a sociedade no espaço escolar.

\begin{tabular}{|c|c|c|c|}
\hline Aula & $\begin{array}{c}\text { Temas } \\
\text { abordados }\end{array}$ & Material utilizado & Proposta da aula \\
\hline $1 \mathrm{~h}$ & $\begin{array}{l}\text { Violência, o uso e } \\
\text { o tráfico de drogas } \\
\text { nas cidades } \\
\text { brasileiras }\end{array}$ & $\begin{array}{l}\text { Isso é Brasil }- \text { MC } \\
\text { Garden (2013); } \\
\text { Documentário Realidade } \\
\text { Brasileira com a música } \\
\text { delação premiada - MC } \\
\text { Carol (2018). }\end{array}$ & $\begin{array}{l}\text { Fazer uma análise do Brasil, principalmente, a negação } \\
\text { dos direitos fundamentais das pessoas mais pobres e a } \\
\text { ligação desses problemas com o tráfico de drogas. }\end{array}$ \\
\hline $1 \mathrm{~h}$ & $\begin{array}{l}\text { Uso de drogas e } \\
\text { criminalização }\end{array}$ & $\begin{array}{l}\text { Cachimbo da paz - Lulu } \\
\text { Santos e Gabriel o } \\
\text { Pensador (2012); } \\
\text { Duas de cinco - Criolo } \\
\text { (2013). }\end{array}$ & $\begin{array}{l}\text { Por meio das músicas refletir sobre o combate as } \\
\text { drogas, os efeitos das drogas e dos vícios e a destruição } \\
\text { das relações sociais do dependente químico. }\end{array}$ \\
\hline $2 \mathrm{~h}$ & $\begin{array}{l}\text { Apresentação } \\
\text { sobre as drogas e } \\
\text { seus tipos }\end{array}$ & $\begin{array}{l}\text { Aula com slide sobre as } \\
\text { principais drogas e seus } \\
\text { efeitos no corpo humano. }\end{array}$ & $\begin{array}{l}\text { Aula expositiva-participativa para explicar os tipos de } \\
\text { drogas, como elas agem e como evitá-las. }\end{array}$ \\
\hline $2 \mathrm{~h}$ & Alcoolismo. & $\begin{array}{l}\text { Explicação sobre os } \\
\text { efeitos do alcoolismo no } \\
\text { corpo e na sociedade. }\end{array}$ & $\begin{array}{l}\text { Aula expositiva-participativa com slides sobre a } \\
\text { dependência da droga lícita álcool e como ela afeta a } \\
\text { vida dos dependentes. }\end{array}$ \\
\hline $1 \mathrm{~h}$ & $\begin{array}{lr}\text { Exibição } & \text { dos } \\
\text { efeitos das } & \text { drogas } \\
\text { na vida dos } \\
\text { adolescentes. }\end{array}$ & $\begin{array}{l}\text { Curta-metragem "A vida } \\
\text { é feita de escolhas } \\
\text { CEEPS (2016)". }\end{array}$ & $\begin{array}{l}\text { O curta-metragem produzido por alunos do PIBID, } \\
\text { simula a vida de um jovem que se tornou dependente } \\
\text { de drogas, a intenção é mostrar os efeitos das drogas na } \\
\text { vida do dependente. }\end{array}$ \\
\hline $1 \mathrm{~h}$ & $\begin{array}{l}\text { Atividade } \\
\text { avaliativa. }\end{array}$ & $\begin{array}{l}\text { Atividade de discussão } \\
\text { sobre o vídeo } A \text { vida é feita } \\
\text { de escolhas, com transcrição } \\
\text { das cenas e falas para } \\
\text { análise e debate em sala. }\end{array}$ & $\begin{array}{l}\text { Atividade de transcrição e escrita sobre o vídeo, os } \\
\text { alunos são instigados a construir uma reflexão sobre a } \\
\text { história contada. }\end{array}$ \\
\hline $2 \mathrm{~h}$ & $\begin{array}{l}\text { A mudança é } \\
\text { possível. }\end{array}$ & $\begin{array}{l}\text { Exibição e discussão do } \\
\text { filme "Escritores da } \\
\text { Liberdade" (2007). }\end{array}$ & $\begin{array}{l}\text { Aula para assistir e discutir sobre o filme Escritores da } \\
\text { Liberdade e a mensagem de motivação que ele traz. }\end{array}$ \\
\hline $1 \mathrm{~h}$ & $\begin{array}{l}\text { Atividade } \\
\text { avaliativa final }\end{array}$ & $\begin{array}{l}\text { Produção de um texto de } \\
\text { opinião com reflexões as } \\
\text { músicas Isso é Brasil e } \\
\text { Delação Premiada. }\end{array}$ & Proposta avaliativa para o aluno e para a SD. \\
\hline
\end{tabular}

Fonte: Dados da Pesquisa, elaborado pelos autores, 2019.

Para apresentação e discussão dessa SD, foram utilizados os métodos das pesquisas qualitativa e descritiva em um relato de experiência. Para Gil (1999), a abordagem qualitativa propicia o aprofundamento da investigação das questões relacionadas ao fenômeno em estudo e das suas relações, mediante a máxima valorização do contato direto com a situação estudada, buscando-se o que era comum, mas permanecendo, 
entretanto, aberta para perceber a individualidade e os significados múltiplos. Segundo Gil (1999), as pesquisas descritivas têm como finalidade principal a descrição das características de determinada população ou fenômeno, ou o estabelecimento de relações entre variáveis.

\section{RESULTADOS E DISCUSSÃO}

\subsection{Enredo de atividades aplicadas durante a SD}

Para essa sequência didática (SD), além da participação nos debates em sala de aula, foi pensando duas atividades diagnósticas. Uma de produção de um enredo e reflexão com produção textual em grupo e outra como avaliação final do que foi aprendido e discutido em sala de aula. As atividades propostas seguem abaixo.

Atividade 1: Agora que aprendemos mais sobre as drogas e suas ações no organismo humano, vamos a parte prática! Você irá assistir ao vídeo de curta-metragem produzido pelos alunos do $4^{\circ}$ ano do curso Técnico em Segurança do Trabalho do CEEPS-Adélia Teixeira em Vitória da Conquista - BA intitulada "A vida é feita de escolhas" no link: https://www.youtube.com/watch?v=tNqi4uGhiCU. Após assistir o vídeo fará a escrita da trama como se fosse o produtor da rede de TV ou streaming que estivesse fazendo uma série! Isso mesmo, você e mais 6 colegas farão a escrita do curta-metragem como se fossem fazer um seriado para a televisão e estivesse escrevendo o roteiro, depois disso, faremos um debate em sala de aula sobre o assunto do vídeo e sua reflexão.

Atividade 2: A proposta era fazer uma produção textual com as duas músicas, a do MC Garden - Isso é Brasil e a da MC Carol - Delação premiada e por meio de um texto de no mínimo 10 linhas por questão argumentar sobre os temas propostos.

a) as músicas do MC Garden e da MC Carol falam sobre as questões socioculturais das periferias brasileiras, existe um grande problema nestas regiões, alguns deles devido a droga. Sobre estas questões faça uma reflexão sobre a temática e trace uma ligação com as duas músicas; b) sobre a estrofe "Violência policial/ Xiu! É melhor nem tocar nesse assunto/ Porque daqui a pouco vão excluir esse vídeo/ E se eu falar muito vão me excluir junto” (MC Garden, 2013), o cantor aborda uma questão muito preocupante no Brasil, que questão é essa? Referente a frase "Esse morreu porque era traficante", é uma questão real ou apenas uma desculpa do governo para não oferecer direitos humanos básicos a essas pessoas? O que você pensa sobre o assunto? Escreva um texto explicando essas questões; c). "Três dias de tortura numa sala cheia de rato/ É assim que eles tratam o bandido favelado/ Bandido rico e poderoso tem cela separada/ Tratamento VIP e delação premiada" (MC Carol, 2016). A estrofe da música delação premiada é enfática ao apontar uma questão social gritante no Brasil, por que isso ocorre? Discorra sobre o tema, o traficante pobre é tratado como o rico? E se for político?

\subsection{Apresentação dos materiais audiovisuais utilizados.}

O clipe e música "Isso é Brasil” (2013), lançado pelo Mestre de Cerimônias (MC) Garden, relata em seus versos realidades brasileiras, faz reflexões acerca das religiões, direitos humanos, violências, política, fome, saúde, abusos sexuais, crimes sem respostas e diversas questões sociais, políticas e ambientais do Brasil. 
O funkeiro é filho de um professor de matemática, envolvido no trabalho voluntário com sua mãe desde muito jovem e diz que sempre teve acesso à realidade social brasileira dentro de casa. $\mathrm{O}$ artista conta que com essa base familiar, continuou a fazer funks, com mensagens politizadas (Cristina, 2016).

A música aparece em um plano de aula da professora Vaccarelli (2016) como material didático para entender que existem diferentes níveis de desenvolvimento socioeconômico e que este é consequência de fatores econômicos, políticos e principalmente históricos. O artista analisa os indicadores socioeconômicos e compreender que crescimento/desenvolvimento econômico é diferente de desenvolvimento social e refletir sobre as condições socioeconômicas do Brasil e da cidade de Curitiba.

O videoclipe de Delação premiada, da MC Carol (2018), conta com imagens do Intercept e já inicia mostrando diversos moradores da favela falando sobre a violência policial que sofrem nas comunidades brasileiras. Uma mãe diz: - "tudo quebrado de tiro, meu filho e meu neto se escondem dentro do guarda-roupa. Perguntou para mim se era o fim do mundo, mãe? Porque o Águia tá vindo e mandando tiro de cima, eu não aguento mais! É paz! É paz pelo amor de Deus!”. Outra cena mostra um morador explicando ao público: "Quando vão prender os grã-finos da Lava-jato, que roubaram da saúde e da educação, que tiraram o salário de vocês, eles vão num carro de luxo".

O clipe ainda mostra outras reclamações sobre os helicópteros da polícia que matam moradores por "bala perdida", casos de assassinato sem respostas, como do Amarildo e do DG (Douglas Rafael da Silva Pereira). As frases enérgicas da música ainda trazem afirmativas fortes, "na televisão a verdade não importa, é negro, favelado, então tava de pistola” (MC Carol, 2016).

O clipe é finalizado por dados das estatísticas do Brasil: “75\% da população carcerária do Brasil são de pessoas negras; em 10 anos, o número de mortes de mulheres brancas caiu $12 \%$, enquanto de mulheres negras subiu 14\%; 70\% das pessoas que vivem na situação de extrema pobreza no Brasil são negras, a cada 12 minutos, uma pessoa negra é assassinada no Brasil, no estado do Rio (RJ) e São Paulo (SP), de 10 pessoas mortas em operações policiais, 7 são negras". A produção audiovisual foi feita por alunos de publicidade da Universidade Veiga de Almeida (UVA), as imagens são do The Intercept Brasil, Filme Tropa de Elite, Filme Era Uma Vez, Inside Rio's Favela, Rede Globo, Made in Brazil, filme O Estopim e do Sistema Brasileiro de Televisão (SBT). As fontes utilizadas para os dados foram o IBGE, A Secretaria de Segurança Pública e o Instituto de Segurança Pública do Rio de Janeiro. O vídeo pode ser acessado em https://www.youtube.com/watch?v=1smJJPekz0c.

A música e videoclipe "Cachimbo da paz" dos cantores Gabriel, o pensador e Lulu Santos, conta a história de um indígena preso por uso de uma erva (alusão a Cannabis sativa: Cannabaceae), popular maconha. Porém, sua reflexão vai muito além do uso desta droga e escancara os problemas de violência policial e abuso de outras drogas, inclusive, as lícitas.

“Os conteúdos de violência presentes na letra referem-se à violência nos grandes centros urbanos, da criminalidade e das consequências do uso abusivo de álcool que gera violência do tipo subjetiva" (Bortolanza \& 
Anzay, 2014, p. 100). A música ainda critica o Estado e as violências cometidas pelos sistemas prisionais, que não reintegram e retroalimentam o ciclo de violência (Bortolanza \& Anzay, 2014).

Já a música "Duas de Cinco" do cantor Criolo, é lida por Andrade (2018) como um rito,

convidando seu público para vestir uma armadura e aceitar ser guiado pelas problemáticas mais profundas do Brasil, que aparecem em suas letras, mas também conduzindo a todos pelo interior da força da cultura negra, pela magia das religiosidades africanas, fazendo uma espécie de feitiço, não dentro do âmbito da religião, mas no âmbito da arte e de todas as suas possibilidades, como um pai de santo que pela força da palavra exerce a feitiçaria, oferecendo diversas formas de lidar com o caos (Andrade, 2018, p. 3733).

"O refrão remete a algo ruim com uma mandinga [feitiço] para o terror, aliado à compra de uma arma com o 'vapor' - gíria utilizada para denominar os jovens que se envolvem com a venda de drogas e armas nas periferias" (Pessoa, 2017, p.42). E assim, a música vai narrando as dificuldades dos jovens das favelas e bairros periféricos.

Em uma crítica poética, a música de Criolo, aborda as drogas lícitas e ilícitas, mostra o álcool, uma droga lícita, que por ser auxiliada pela mídia, propagandas e a sociedade, se torna uma necessidade e, é tolerada (Pessoa, 2017): "Comerciais de TV/ Glamour pra alcoolismo/ E é o kinect do Xbox por duas buchas de cinco" (Criolo, 2014).

\footnotetext{
Além disso, a menção ao kinect do Xbox "sensor de movimento de vídeo game, representa a venda desse objeto de alto valor por duas buchas de cinco, ou seja, duas porções de cocaína equivalentes a cinco reais cada. Remetendo a uma causa em prol do vício, que podem ser o furto e venda de objetos pessoais para a compra de drogas" (Pessoa, 2017, p. 46).
}

Nesse sentido, a música serve para refletir sobre o uso de drogas, a realidade do jovem periférico e todas as problemáticas socioculturais atreladas ao assunto no Brasil, como a pobreza, a miséria, a violência simbólica e a violência, propriamente dita.

O rapper conta em suas letras com a presença dos dois universos, unindo elementos consumistas, orgulho racial, críticas políticas, alienação das massas por meio da mídia, a qual ele também pertence, aliada a diversos recursos poéticos e estilísticos que fazem de suas músicas um canto poético engajado e atual (Pessoa, 2017, p.50).

O recurso visual $A$ vida é feita de escolhas é um curta-metragem produzido por alunos do $4^{\circ}$ ano do curso Técnico em Segurança do Trabalho, do Centro Estadual de Educação Profissional em Saúde Adélia Teixeira (CEEPS-AT), no ano letivo de 2016, por meio de atividades do Programa Institucional de Bolsa de Iniciação à Docência (PIBID). O vídeo conta a história de um jovem que se envolve com o uso de drogas e sofre com as consequências dessa escolha (Silva \& Ferreira, 2017).

O curta-metragem também pode ser reproduzido em forma de teatro por alunos ou adaptado para outras possíveis intervenções em sala de aula, na SD aplicada foi exibido e pedido aos alunos que transcrevessem as cenas para criar o enredo e fizessem uma reflexão sobre o uso de drogas e seus problemas na via do adolescente.

O último recurso audiovisual utilizado na SD foi o filme Escritores da Liberdade (2007), dirigido por Richard LaGravenese, “aborda o conflito da questão social com a metodologia ineficaz de educação do sistema capitalista, onde os sujeitos inseridos neste contexto gritam por uma identidade perante a sociedade" (Lemos \& 
Barboza, 2008, p.1). O filme aborda rivalidades entre as etnias e a xenofobia na escola após alunos de classe pobre frequentarem uma escola de classe média estadunidense e as dificuldades que as pessoas da periferia enfrentam no sistema capitalista, a intenção da professora Srta. Erin Gruwell é buscar a verdadeira identidade do aluno, procurando desmembrar gangues e a xenofobia existente (Lemos \& Barboza, 2008).

\subsection{Momento das aulas}

Aula 1: Violência, o uso e o tráfico de drogas nas cidades brasileiras. Nesse primeiro momento, foi apresentado a proposta de trabalho e abordou-se sobre os problemas que o uso de drogas causam na sociedade e na saúde dos usuários. Com a exibição dos clipes "Isso é Brasil" e "Delação premiada" abriu-se o debate para o tratamento que a polícia e a justiça brasileira direcionam para as pessoas de diferentes classes sociais e a forma como o crime é analisado a depender dessas características.

Estudante A - "a polícia não pergunta a uma pessoa pobre o que ela está carregando, já chega dando tapão".

Estudante B - "a gente observa que quando vai prender rico não tem toda a violência que é imposta ao preto que mora nos bairros de pobre".

Estudante C - "a música de MC Garden é uma realidade do Brasil, vemos muito isso e também tem gente que não se valoriza, a polícia tá errada, mas tem gente também que esculbamba".

Aula 2: Uso de drogas e criminalização. Por meio da exibição e debate dos dois clipes, "Cachimbo da paz" e "Duas de cinco" foram levantados questionamentos sobre os efeitos das drogas na vida do usuário e quais as ações que a pessoa e a sociedade fazem para combater ou ajudar o usuário.

Estudante A - "depois que o cara fica viciado é muito difícil para a família, não se controla mais."

Estudante D - "o cachimbo da paz, acho que é a maconba, eu sei que muito rico usa e ninguém fala nada, mas vai um pobre usar pra você ver..."

Estudante $\mathbf{F}$ - "a gente vê que o homem vende o negócio do videogame e isso é mesmo professor, tem um homem lá na minha rua que vende tudo de casa pra comprar drogas".

Aula 3: Apresentação sobre as drogas e seus tipos. Nessa aula foram explicadas o que são drogas, como elas agem no organismo e causam dependência, que o consumo contínuo de drogas, além de ocasionar a morte do indivíduo quando em altas quantidades (overdose), pode ocasionar sérias sequelas no sistema nervoso (lesões neuronais), no circulatório (tensões arteriais) e respiratório, bem como problemas de ordem social, envolvendo a marginalização de adolescentes atraídos pelo tráfico.

Ademais, foi apresentada a classificação das drogas como: a) depressoras - podem dificultar o processamento das mensagens que são enviadas ao cérebro. Exemplos: álcool, barbitúricos, diluentes, cloreto de etila, clorofórmio, ópio, morfina, etc. b) psicodislépticas ou alucinógenas - têm por característica principal a despersonalização em maior ou menor grau. Exemplos: maconha, skunk, LSD, psilocibina, heroína. c) psicoanalépticas ou estimulantes - produzem aumento da atividade cerebral, diminuem a fadiga, aumentam a percepção ficando os demais sentidos ativados. Exemplos: cocaína, crack, cafeína, teobromina, MDMA ou ecstasy, anfetaminas (bolinha, arrebite), etc. 
Após isso, foram explicadas sobre as drogas cocaína, maconha, crack, ecstasy e álcool, suas composições químicas, efeitos e formas de prevenção.

Aula 4: Alcoolismo. Durante essa aula foi trabalhado a dependência do álcool e as formas de prevenção ao abuso dessa droga lícita. A Organização Mundial da Saúde já apontou que nosso país, e na maioria dos países da América Latina, o consumo de bebidas alcoólicas é responsável por cerca de 8\% de todas as doenças existentes (Antidrogas, 2016).

Apesar do Estatuto da Criança e do Adolescente (ECA) proibir a venda de bebidas alcoólicas para crianças e adolescentes em seu Artigo 81, Lei 8.069 de 1990 (Brasil, 1990), ainda existe muita venda clandestina e consumo exagerado por esse grupo social.

Entre os motivos alegados para o uso, pode-se destacar curiosidade; necessidade de pertencer a determinado grupo, diminuir inibições, adquirir coragem, tratar problemas médicos, relaxar para lidar com problemas; rituais religiosos e obtenção de prazer (Albernaz \& Passos, 2001; Sanchez et al., 2004). Nesse sentido, a aula serviu para mostrar os efeitos do uso abusivo das bebidas alcoólicas e os riscos de se tornar alcoolista.

Aula 5: Exibição dos efeitos das drogas na vida dos adolescentes e atividade avaliativa. Em um primeiro encontro foi exibido o vídeo "A vida é feita de escolhas" na sala de aula e dividido os grupos para a proposta da Atividade 1. Na segunda aula, os alunos já haviam feito o trabalho proposto e trouxeram o enredo do curtametragem aqui apresentada:

"Filme $A$ vida é feita de escolhas!

$1^{a}$ Cena: Sala de aula.

O curta inicia com o narrador:

- "Que pena, que droga de vida, que droga de escolha"...

Após isso vai para uma cena em sala de aula:

Professor:

- Galera, todos abram o livro na página 54 e façam a atividade do 01 ao 07 e me entreguem ainda pra hoje, tá? Gustavo:

- Mô, eu vou sair um pouco mais cedo, viu?

Laura:

- Ab, tá, tudo bem.

Gustavo:

- Ai você termina pra mim, que eu copio depois de você.

Laura:

- Tá bom então.

Gustavo:

- Ai você manda a foto.

João:

- Pồ véi', também vou.

Gustavo:

- Então bora, vamos simbora, bora lá.

Laura:

- Tchau, mô.

Gustavo:

\footnotetext{
${ }^{1}$ A gíria "véi" é muito utilizada pelos adolescentes de Vitória da Conquista, Bahia, é empregada para conversas com pessoas que se consideram um grande amigo, irmão.
} 
- Ab é né? Tem isso, tchau!

Laura:

- Tchau, quando chegar me avisa.

Gustavo:

- Certo!

Laura:

- Tá.

Gustavo:

- Partiu mesmo

João:

- Bora, hashtag partiu.

$2^{\text {a }}$ cena: Encontro com o grupo que usa drogas para recreação.

Já fora da sala de aula os dois caminham para ir colocar créditos no cartão escolar. Gustavo:

- Poxa véi, ainda bem que "nóis saiu" dessa aula, não suporto essa aula chata, mano.

João:

- Só história...

Gustavo:

- Toda hora passando prova velho, não dá certo não, véi.

João:

- Vai botar crédito no cartão?

Gustavo:

- Vamos lá, bora lá.

João:

- Bora lá pô, devagar.

Saindo da escola, os dois encontram um outro grupo.

João:

- Oi.

Gustavo:

- E aí irmão, beleza?

Luan:

- E aí, pivete.

O Grupo vai repetindo gírias enquanto se cumprimentam:

- Boa, tudo bem? E aí, fechou, show e aí.

João:

- E aí, o que vocês contam pra nós?

Rodrigo:

- Velho, tô com um bagulho muito doido aí, você tem que vir com "nóis", clarear a mente.

Gustavo:

- Clarear a mente? Como assim, mano?

Rodrigo:

- Bora lá, bora lá.

Gustavo:

- Bora, bora então né véi.

Rodrigo:

- Bora.

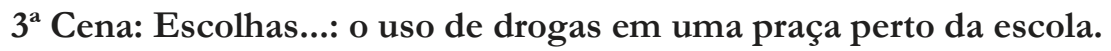
Narrador:

"Alguns dizem que foi por influência, en digo que foi por minha culpa, nada mais". A cena muda para uma praça perto da escola.

Rebeca:

- Ai pivete, eu vou te apresentar uma parada muito massa, e você vai gostar, tá ligado? João:

- E aí.

O grupo:

- Calma aí. 
Gustavo:

- O que tem pra nós?

Grupo:

- Vai, vai!

João:

- Bora lá.

Cada um pega uma droga e usa um pouco e repassa para os outros, Gustavo usa e se engasga, começando a tossir.

Grupo:

- Engasgou. Todos riem. - Ah, não aguentou não.

Rebeca:

- E ai, gostou? O bagulho é louco.

Rebeca:

- Quer de novo? Dá mais uma tragada aí vai, véi.

Gustavo:

- É nós, ô, já é.

$4^{a}$ Cena: "Do vício ao fundo do poço".

Narrador:

"Troquei pessoas que amo por um prazer doentio".

Laura e a mãe de Gustavo vão atrás dele na rua e o encontra jogado no chão.

Laura:

- Eu vi ele por ali tia, por algum lugar aqui tia, eu vou tentar ligar para ele, eu vou tentar, não nada. Eu não tô conseguindo.

Mãe do Gustavo:

- E agora? O quê que a gente vai fazer?

Laura:

- Não sei!

Quando elas o encontraram ele estava totalmente atormentando, elas correm em sua direção, gritando.

- Meu filho!

- Meu amor!

- Meu amor!

Gustavo atormentado e apresentando sinais do uso de drogas:

- Sai, sai, saaiii.

Laura:

- Não, o que aconteceu com você?

Mãe do Gustavo:

- Meu filho, meu filho!

Gustavo:

- Não sei mano, não quero não, não quero saber, sai mano, sai mano, sai.

Laura encontra a droga com ele e o pergunta:

-O que é isso? Você nunca foi disso, o que é?

Gustavo:

- Cigarro mano, cigarro.

Laura:

- Você tem que parar com isso!

Gustavo:

- Calma, mano.

Laura:

- Não, não.

Gustavo:

- Sai, sai, não, sai.

Laura:

- Amor, não, não, olha pra mim, você não pode, você nunca foi disso, para a gente precisa conversar, precisa internar você em uma clínica.

Gustavo fica totalmente furioso e corre em outra direção.

5 Cena: Até onde vai parar? Compra de drogas em uma boca de fumo. 
Vários garotos vão em uma casa à noite, em busca de drogas.

Rodolfo:

- Cadê aquele bagulho de novo?

Mariano:

- Rapaz, tô doido pra pegar um pozinho...

Eles batem em uma porta, para comprar mais drogas, o vendedor aparece e os cumprimentam, compram a droga e vão embora...

Traficante:

- Cadê o dinheiro, cadê o dinheiro. Entrega as drogas.

Gustavo vai à casa do "parça" (traficante) dele, em busca de drogas, mas ele está devendo na boca...

O traficante diz:

- Sabe que tá devendo na boca, né?

Gustavo:

- Eu sei, o patrão está pegando no meu pé por conta disso, mas me arruma estou precisando mesmo, estou louco...

Traficante:

- Opatrão, véi, te mandou até um áudio aqui ó, escuta aqui.

Gustavo ouve o áudio na rede social.

- Puta merda, mano, toma, mano, sério véi, me arruma os bagulhos aí, o patrão não vai ficar nem sabendo...

O traficante diz:

- Velho, como você já é brother das antigas tem umas ruazonas aí abaixo, escura, cheia de playboy, vários peixes lá, dá pra você pescar, toma até uma arma (faca) aqui e pá.

Gustavo:

- Valeu!

Então, passa um rapaz andando pela estrada escura com um celular e se depara com Gustavo que o aborda.

Gustavo:

- Perdeu, perdeu, bora, bora...

Rapaz:

- Quê isso? Eu vou entregar.

Gustavo:

- Vaza, vaza, vaza. Gustavo rouba o celular.

O rapaz corre e encontra um homem que pergunta o que foi:

- Me assaltaram ali, responde o rapaz.

O outro responde:

- Calma, eu sou polícia, pera aí.

O policial, à paisana, corre e encontra Gustavo:

- Foi você que assaltou o menino não foi? Parado porra, parado! Ajoelha filho da puta, seu filho da puta! Filho da puta! O policial agride Gustavo com socos.

Gustavo grita desesperado:

- Calma, calma, para, para...

A cena se encerra.

$6^{\mathrm{a}}$ Cena: encerramento dramático.

Aparece a frase:

"Saibamos que toda escolha, sejam positivas ou negativas, implicam em consequências".

Na verdade, para mim, tudo se resume a quem eu quero ser e quais as consequências que estou disposta a enfrentar".

Narrador:

"A vida é feita de escolhas", assim é dito por várias pessoas ao redor do mundo. Posso dizer que fiz a minha escolha, porém, não foi a mais sábia, muito menos a mais correta.

Troquei pessoas que amo por um prazer doentio, um vício quase incontrolável. Alguns dizem que foi por influência, eu digo que foi por minha culpa e nada mais. Realmente, minha história não tem um final feliz, o mesmo com outras pessoas que passam, passaram ou passarão por isso, só Deus sabe o que é isso.

É realmente um inferno perder as pessoas que amamos por escolhas mediocres. Como é isso? Isso é como um câncer, um câncer que não pode ser destruído, pelo contrário, é ele que lhe destrói de dentro para fora. Meu fim é como um conto, mas não um conto feliz, jogado como uma carne morta em meio a rua, onde as pessoas passam e repassam e em seus rostos, trazem consigo a agonia, desespero, pena, mas apenas isto, apenas olham, ninguém sente a sua falta, a não ser as pessoas que você virou as costas. É tudo tão rápido e inacreditável... hoje você vive e amanhã você morre. Não, não, é a morte que a alma abandona o corpo, mas a morte que em você abandona a si 
mesmo. Engraçado como eu tinha tudo, mas agora não tenho nada, nada, nada. Perdi meus ideais, crenças, vida, a vida é feita de escolhas. Sinto muito mesmo por não ter escolbido a certa, que pena, que droga de vida, que droga de escolha.

Ao fim, mostra Gustavo perdido na rua, sem família, sem droga... sem nada". (Enredo do vídeo "A vida é feita de escolhas" escrito pelos alunos da EJA, $8^{\circ}$ e $9^{\circ}$ anos do Ensino Fundamental II, 2019).

Por fim, os alunos debateram e construíram uma reflexão coletiva sobre o que foi assistido

"Na vida somos nós que decidimos o que queremos, não se deve confiar em qualquer amizade, alguns amigos só querem te levar para o caminho errado. Esse caminho acaba destruindo você e sua família.

Esse caminho acaba levando você para cadeia ou a morte, deixa você viciado, perdendo família, amigos, namorada e outras pessoas importantes na sua vida... você aprende a roubar para sustentar seu vício, que aumenta cada vez mais, todos os amigos que te levam para essa vida, quando você precisar não estarão lá para te ajudar, então pensar duas vezes antes de fazer aquilo que possa te causar a perda de amigos.

Porque a vida, ela é feita de escolhas, e uma delas pode até te levar a morte, porque começa tudo por um bobo baseado, ai te leva a ficar viciado, quando você for atrás para querer usar eles te obrigam a roubar, a matar, ou seja, em uma escolha errada que você não pensou antes de entrar, quando perceber que não valia a pena, já é tarde demais" (Texto escrito pelos alunos da EJA, $8^{\circ}$ e $9^{\circ}$ ano do Ensino Fundamental II, 2019).

Pelo envolvimento dos educandos e a pré-disposição em criar o enredo do filme e em fazer uma reflexão sobre a narrativa, o uso de mídias mostrou-se alternativa de método de ensino em sala de aula. Ribeiro (2009), aponta que com o crescimento da utilização de mídias nos processos educacionais mostra-se a necessidade de que as práticas pedagógicas estejam próximas da realidade social do aprendiz, estimulando o prazer pela escrita e pela leitura mediante o uso de representações diversas, como sons e imagens. Vale apontar que "as aulas com dinâmicas diferentes permanecem na memória dos educandos e influenciam positivamente na formação científica, cultural e cidadã dos envolvidos, ao mesmo tempo vence a tradicionalidade dos métodos avaliativos” (Silva, 2019, p. 19).

Aula 6: A mudança é possível. Nessa aula a intenção foi demonstrar que a mudança é possível, que mesmo vivendo em bairros periféricos a educação pode ser uma ponte para o futuro e o sucesso na vida longe das drogas. Após a exibição do filme Escritores da Liberdade foi aberto um debate e nesse momento, ao perguntar, - "O que vocês acharam do filme?" Um dos alunos respondeu:

- "Ela (a professora) queria fazer com os alunos dela o que você tá fazendo com a gente". (Estudante A).

Com a emoção estampada no rosto e devidamente agradecido, o debate foi continuado.

- "A professora mostrou aos alunos que a mudança é uma coisa possivel" (Estudante F).

- "A cena que a "prof" mostra que eles são iguais e devem ser respeitar é muito massa". (Estudante G).

Por meio dessa aula foi possível perceber que os alunos haviam entendido o recado de não uso de drogas, a participação e o comportamento de todos foi notável, mostravam-se seguros e tranquilos para debater sobre o assunto, sem o "medo" de falar o que pensavam. Assim como no filme, "o método utilizado pela professora fez com que os alunos se desarmassem perante o ensino e desabrochassem perante a sociedade, perante, sobretudo, suas próprias vidas” (Lemos \& Barboza, 2008, p.2).

Aula 7: Produção textual avaliativa. A última aula foi avaliativa. Com o uso da atividade 2 (Vide metodologia) proposta, os alunos puderam expressar seus aprendizados, foram transcritos algumas para melhor visualização do aprendizado construído. 
"Na sociedade em que vivemos é muito comum isso que está sendo refletido nas duas músicas, acontecem a todo momento, na frente da população, mas quando as pessoas vão questionar, alguns desaparecem, outros são mortos, o que está sendo retratado nas duas músicas são mais comuns em favelas ou bairros periféricos por conta da pobreza das pessoas que não podem fazer muita coisa quando isso ocorre é por conta disso que muitos jovens opinam (escolhem) pelo lado do tráfico, roubo, etc.” (Estudante $\mathrm{H})$.

"As músicas retratam que o grande problema não está nas "drogas" e sim no preconceito, a cor e ao fato de ser rico ou um simples negro favelado, muitas vezes pessoas direitas são mortas pelo simples fato da cor da pele, muitas crianças e jovens todos os dias são impedidos de ter um ensino de qualidade, um futuro digno, tendo que iniciar no mundo do crime desde muito cedo, mas os políticos não estão preocupados com esse triste fato, tem medo de uma geração de pensadores, o grande futuro do Brasil é a educação, mas é um grande caos, nem os professores são respeitados como deveriam ser". (Estudante I).

"Nas duas músicas podemos entender muito bem o que a elas se referem. O problema com drogas na periferia e o preconceito com as pessoas que vivem lá, serem todas iguais, acham que todos são bandidos. Na música do MC Garden fala sobre o Brasil em que vivemos, que o corpo vale mais que a mente, autoridades passando dos limites, problemas com saúde e entre outros. Já na música de MC Carol, podemos ver que tem uma ligação com a música anterior, sobre o preconceito na favela com os negros. Injustiça e casos de mortes não solucionadas". (Estudante J).

"No Brasil existe muito a parte de quem é rico e a de quem é pobre, isso define muitas pessoas no Brasil. Aqueles que são ricos são tratados melhores do que os pobres, até hoje isso acontece.

Também há questão da cor, as pessoas que moram em favelas, para a policia, por a pessoa ser negra têm mais chance de começar a usar drogas e isso não é verdade. Até na cadeia as pessoas ricas são bem tratadas, agora as pessoas negras e pobres são totalmente diferentes, ficam em salas com ratos e etc. para eles, toda pessoa negra é bandida e não é assim. Tem policial que mata tanta pessoa inocente em favelas só por causa de suas cores, acha que são bandidos" (Estudante K).

"O mundo na atualidade é um mundo totalmente "escroto" onde existem muitas diferenças, onde há muita violência, um mundo hipócrita. As músicas relatam a realidade vivenciada, onde o preto não tem direito a nada, a violência é muito grande devido as drogas e se for preto e favelado não tem direito a nada. Em termos de religião, são demonstradas as diferenças em que algumas são honestas e outras não. A droga é o que mais prejudica a sociedade, por conta dela muitos morrem ou matam, sujam suas mãos ou a calçada. Os ricos são VIPS da história, cometem crimes, mas são tratados como reis, enquanto um pobre é desprezado, maltratado por ser pobre, negro e favelado" (Estudante L).

Nesse contexto, os textos partem de percepções do cotidiano dos jovens, de sensações e interpretações do seu bairro, das histórias contadas e dos casos de violência urbana que fizeram conexão enquanto ouviam a música. Dessa forma, vai se desfazendo a história única contada a todo momento pela televisão, pelos blogs e por boatos, o aluno pode expressar a sua individualidade e a sua percepção acerca do tema proposto.

Como diz Adichie (2019, p. 33) "quando rejeitamos a história única, quando percebemos que nunca existe uma história única sobre lugar nenhum, reavemos uma espécie de paraíso". Desse modo, os alunos ao refletirem sobre seu espaço de morada, seus problemas sociais, ao pensar e repensar como as drogas aparecem nos noticiários, principalmente quando envolve pessoas pobres e pretas e suas narrativas, vão desconstruindo conceitos pré-estabelecidos e sabem que o caminho para o combate as drogas perpassa por movimentos de educação, combate ao racismo, a negação de direitos humanos básico, sobretudo aos mais necessitados, além política públicas de saúde, segurança e bem-estar social firmes e integrativas. 


\section{CONSIDERAÇÕES FINAIS}

A SD e suas atividades propostas com a utilização de mídias em sala de aula se mostraram de bom aproveitamento levantando importantes debates sobre problemas sociais que transpassam reflexões no combate as drogas. Com as letras de músicas populares de estilos que permeiam o funk, o rap e o hip hop foi possível fazer uma aproximação com os estudantes, que apresentaram interesse nas discussões propostas pelos versos, sons e imagens que constituem as obras audiovisuais.

Por meio dos filmes "A vida é feita de escolhas" e "Escritores da Liberdade" foi possível mergulhar nas realidades de um adolescente que se envolveu com o uso de drogas por uma escolha de vida fora da escola e com a experimentação de entorpecentes que o levou a iniciar na vida do crime e acabou vivendo nas ruas e conhecer as dificuldades de jovens estadunidenses de origens cambojanas, latinas e africanas que vivem em guerra por questões xenofóbicas e por meio de uma professora que os incentivaram conseguem mudar essa realidade. A partir disso, os alunos conseguiram refletir sobre problemas com drogas e interligar com as problemáticas sociais, raciais, políticas, de saúde etc.

A prática relatada apresenta importância para a reflexão do papel da educação e do impacto que ações adequadas e bem articuladas podem fazer uma educação de qualidade, assim, promovendo a criticidade e emancipação de sujeitos. Por fim, a SD apresentada mostrou-se um processo didático auxiliar no processo de ensino e aprendizado e fica como sugestão a ser trabalhada em outras turmas para possíveis ampliações e ajustes do projeto.

\section{Agradecimentos}

A todos os alunos que participaram das atividades, especialmente a Erick Martin Winner (in memoriam), o aluno que interpretou o professor no curta $A$ vida é feita de escolhas enquanto era meu aluno pelo PIBID e foi levado tão jovem pela violência urbana.

\section{Conflitos de interesses}

Os autores declaram que não há conflitos de interesse. Todos os autores estão cientes da submissão do artigo.

\section{REFERÊNCIAS}

Adichie, C. N. (2019). O perigo de uma bistória única. São Paulo/SP: Companhia das Letras.

Albernaz, A. L. G. \& Passos, S. R. L. (2001). Uso de substâncias psicoativas. In: Coutinho, M. F. G. \& Barros, R. R. Adolescência: uma abordagem prática. Atheneu. 
Andrade, L. T. (2018). Reflexões sobre a performance a partir do rap-canção de Criolo. In: Congresso Internacional Circulação, tramas \& Sentidos na Literatura: Associação Brasileira de Literatura Comparada.

Antidrogas. SOS Vida. (2016). Impacto das drogas na sociedade brasileira - busca de soluções. Obtido em: http://www.antidrogas.com.br/mostrasosvida.php?c $=52$

Bortolanza, G. E. \& Ansay, N. N. (2014). A emergência de conteúdos de violência presentes nas letras de músicas escutadas pelos jovens. Revista Brasileira de Musicoterapia, 14(17), 86-108.

Bourdieu, P. (1989). O poder simbólico. Editora Bertrand Brasil. Rio de Janeiro.

Brasil. (1990). Lei ñ 8.069, de 13 de julho de 1990. Dispõe sobre o Estatuto da Criança e do Adolescente e dá outras providências. Obtido em: http://www.planalto.gov.br/ccivil 03/leis/18069.htm

Criolo. (2014). Duas de cinco. Convoque seu Buda. São Paulo: Oloko Records. Obtido em: https://www.youtube.com/watch?v=QnCs2nsZGRk

Cristina, P. (2016). A música consciente de MC Garden. Revista Arruaşa, 1(4), 1-4.

Debord, G. (2003). A sociedade do espetáculo (1931-1994). Projeto Periferia.

Garcia, M. L. T.; Leal, F. X. \& Abreu, C. C. (2008). A política antidrogas brasileira: velhos dilemas. Psicologia \& Sociedade, 20(2), 267-276.

Gil, A. C. (1999). Métodos e técnicas de pesquisa social. (5. ed). São Paulo: Atlas.Lemos, A. S. \& Barboza, L. M. (2008).

Escritores da Liberdade (Freedoom Writers, EUA, 2007). Revista Ensaios, 1(1), 1-2.

Lima, J. M. B. (2010). Combate às drogas: fracasso anunciado. Revista da EMERJ, 13(51), 297-303.

Lipovetsky, G. \& Serroy, J. (2013). A estetização do mundo: viver na era do capitalismo artista. Companhia das Letras. São Paulo: Editora Schwarcz S. A.

Marghoti, A. M. et al. (2018). Educação, adolescentes e uso de drogas: abordagens necessárias. Florianópolis: Gráfica Coan.

MC Carol. (2016). Delação premiada. Bandida. Heavy Baile Records. Rio de Janeiro, 2016. Obtido em: https://www.youtube.com/watch?v=ZfZLPXLGwUs

MC Garden. (2016). Isso é Brasil. 2016. Independente. Rio de Janeiro, 2013. Obtido em: https://www.youtube.com/watch?v $=\mathrm{nRF0QLYYCe4}$

Moura, M.A.; Peruna, A.M.S.; Freitas, M.S \& Almeida, O. A. (2017). Sequência didática sobre anatomia bumana aplicada pelos bolsistas do PIBID: um relato de experiência. In: Seminário Gepráxis, Vitória da Conquista, Bahia, Brasil, 6 (6), 2995-3006.

Movimentos. (2017). Movimentos: drogas, juventude e favela. [s.l.].

Pessoa, M. (2017). A poética nas canções de Criolo: rap e vivências. Universidade Tecnológica Federal do Paraná. Departamento de Letras. Curso de Licenciatura em Letras Português-Inglês. Pato Branco: Paraná.

Ribeiro, L. S. (2009). Elaboração do gênero roteiro cinematográfico com o uso de mídias na sala de aula. Revista dos Alunos da Graduação em Letras: Ao Pé da Letra, 11(2), 141-156.

Sanchez, Z.; Van Der Meer, O. L. G. \& Nappo S. A. (2004). Fatores protetores de adolescentes contra o uso de drogas com ênfase na religiosidade. Rio de Janeiro: Ciência: Saúde Coletiva, 9(1), 43-55. 
Silva, M. O. (2019). Lourinha e sua turma: os quadrinhos como metodologia de ensino em temáticas socioambientais. Educação Ambiental em Ação, 17(67), 1-15.

Silva, M. O. \& Ferreira, V. B. A. V. (2017). Debates sobre os riscos das drogas e suas formas de prevenção: um projeto do PIBID Interdisciplinar. In: V Seminário Institucional do Projeto Micro rede Ensino-Aprendizagem-Formação (PIBID-UESB): PIBID: Formação, Pesquisa e Prática. Itapetinga-Vitória da Conquista, Bahia, 1105-1109.

Vaccarelli, E. A. (2016). A música como recurso pedagógico no ensino da geografia: subsídios à análise das transformações socioespaciais causadas pelo processo de globalização. In: Os desafios da escola pública paranaense na perspectiva do professor PDE: Produções didáticos-pedagógicas. Governo do Paraná. Curitiba: PR, (1).

VI Levantamento Nacional sobre o Consumo de Drogas Psicotrópicas entre Estudantes do Ensino Fundamental e Médio das Redes Pública e Privada de Ensino nas 27 Capitais Brasileiras. (2010). In: Carlini, E. A. et. al. CEBRID - Centro Brasileiro de Informações sobre Drogas Psicotrópicas: UNIFESP - Universidade Federal de São Paulo. SENAD - Secretaria Nacional de Políticas sobre Drogas, Brasília - SENAD, 503 p.

Zabala, A. (1998). A prática educativa: como ensinar. Porto Alegre: Artmed. 